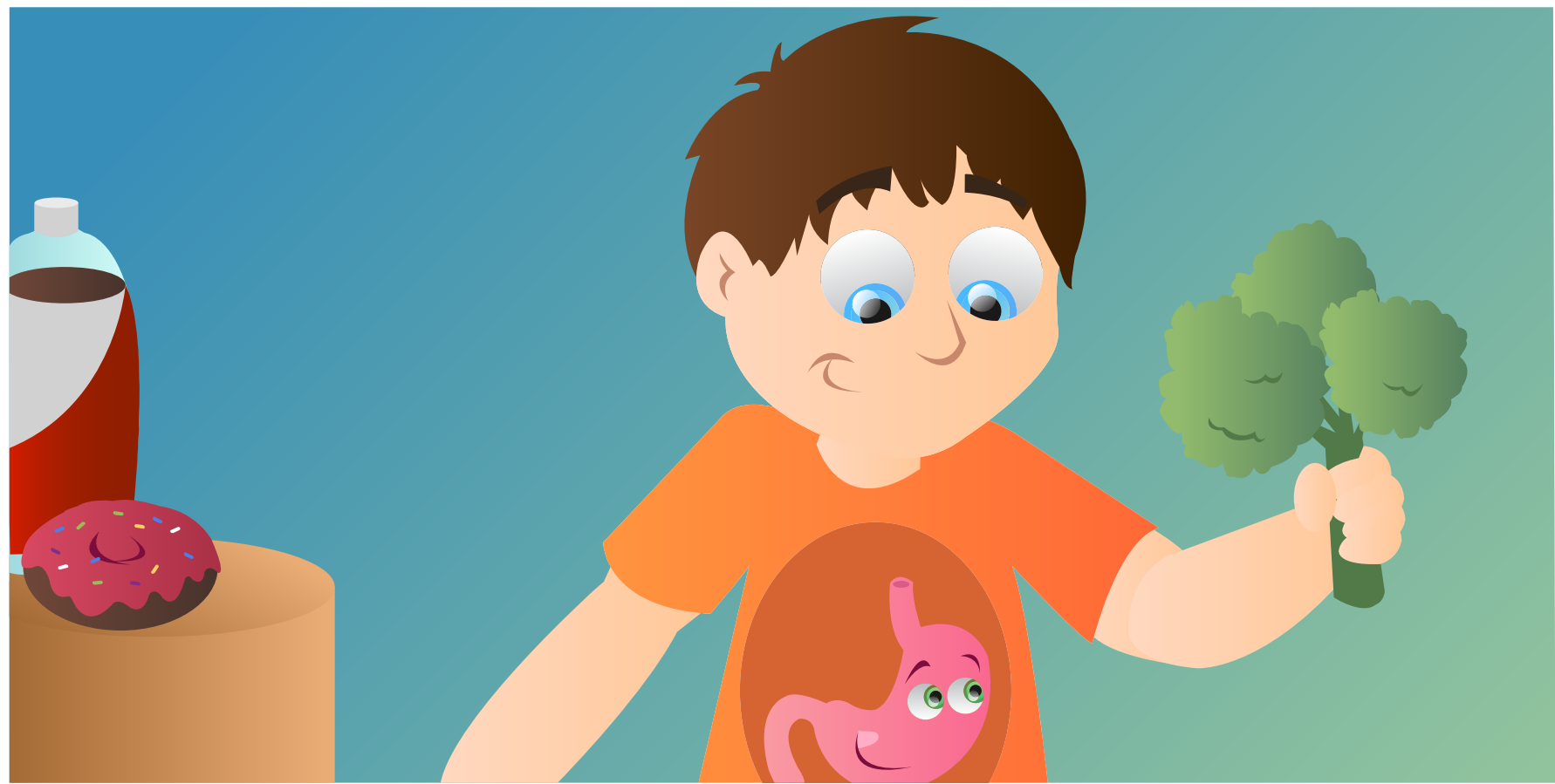

\title{
WE ARE NEVER ALONE: LIVING WITH THE HUMAN MICROBIOTA
}

\section{Gabriela Jorge da Silva*and Sara Domingues}

Faculty of Pharmacy and Center for Neurosciences and Cell Biology, University of Coimbra, Coimbra, Portugal

\section{REVIEWED BY: \\ JACK AND \\ ADDY \\ 7 AND 6 YEARS \\ OLD \\ MICROBES/ \\ MICROORGANISMS \\ Mostly one-celled organisms that include bacteria, some fungi (such as yeast), and microalgae.}

The human body is inhabited by millions of tiny living organisms, which, all together, are called the human microbiota. Bacteria are microbes found on the skin, in the nose, mouth, and especially in the gut. We acquire these bacteria during birth and the first years of life, and they live with us throughout our lives. The human microbiota is involved in healthy growth, in protecting the body from invaders, in helping digestion, and in regulating moods. Some changes in the microbiota may occur during our growth, depending on the foods we eat, the environment in which we live, the people and animals that interact with us, or medicines that we take, such as antibiotics. The human microbiota helps us to keep us healthy, but sometimes these bacteria can also be harmful. We need to take good care of our microbiota to avoid the development of some diseases, such as obesity and asthma. We should eat healthy foods that contribute to the development of a healthy microbiota.

We live with and surrounded by microbes (also called microorganisms), even though we cannot see them with our eyes. Microbes are the smallest living 


\section{BACTERIA}

Tiny living microorganisms that can be beneficial or dangerous for people.
HUMAN

\section{MICROBIOTA}

The group of microbes that live in the human body and do not cause disease.

\section{COLONIZATION}

Living in the body without causing any harm.

\section{FIGURE 1}

Shapes of bacteria. A. Bacteria can be round like a basketball, long like a baseball bat, or can look like beans or waves.

Sometimes bacteria can group together and look like a bunch of grapes or like a train. B. Bacteria can be seen using a microscope with $1,000 x$ magnification. Staining is often used to help see the bacteria, which are actually transparent. Bacteria colored in pink are called bacilli and those in purple are called cocci. organisms known. They are everywhere: in soil, rivers, plants, animals, tap water, on your keyboard, on your pillow and in your body. Some microorganisms live with us and inside our bodies. Bacteria represent the majority of the microorganisms living in the body. Did you know that you have more bacteria in your body than you have human cells? Do you have any idea why these bacteria live in your body? We carry these neighbors with us every day and usually they do not make us sick. Are they friendly? Or can they make us ill? How do they get in? What is their role in the body?

\section{WHAT ARE BACTERIA?}

Bacteria are tiny living microorganisms that are too small to be seen by the naked eye. They are a 1,000 times smaller than a pencil tip. We have to use an instrument called a microscope, which makes the image of the bacteria big enough to be seen. There are many different kinds of bacteria with diverse shapes and sizes. Some look like a baseball bat, others are round like a basketball (but millions of times smaller) (Figure 1).

\section{WHERE ARE BACTERIA IN THE HUMAN BODY?}

Bacteria live on the skin, inside the nose, in the throat, in the mouth, in the vagina, and in the gut. The majority of the bacteria found in the body live in the human gut. There are billions of bacteria living there (Figure 2). We call the group of all the microbes found in the body the human microbiota [1]. These microorganisms colonize the body, which means that they usually do not cause any harm. When a microorganism causes sickness, that is called an infection.

\section{WHERE DO THE BACTERIA THAT LIVE IN THE HUMAN BODY COME FROM?}

We begin to be colonized by bacteria during birth. During the birth process and immediately after birth, we get our first microorganisms. Babies get

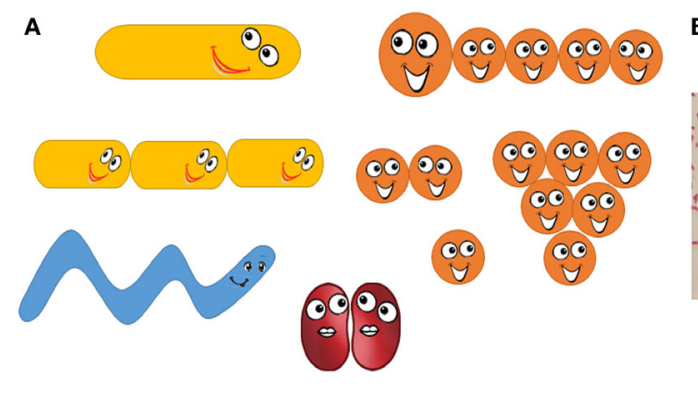

B

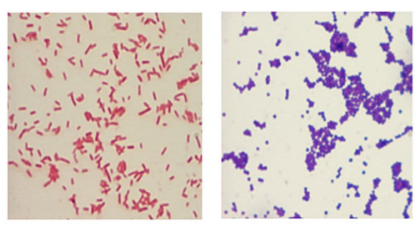

FIGURE 1 


\section{FIGURE 2}

The human body is the home of millions of bacteria.

Several body sites are full of bacteria and they are especially concentrated in the gut, in the throat and mouth, and on the skin.

\section{DIGESTION}

To break down food into small pieces to be used by the human body.

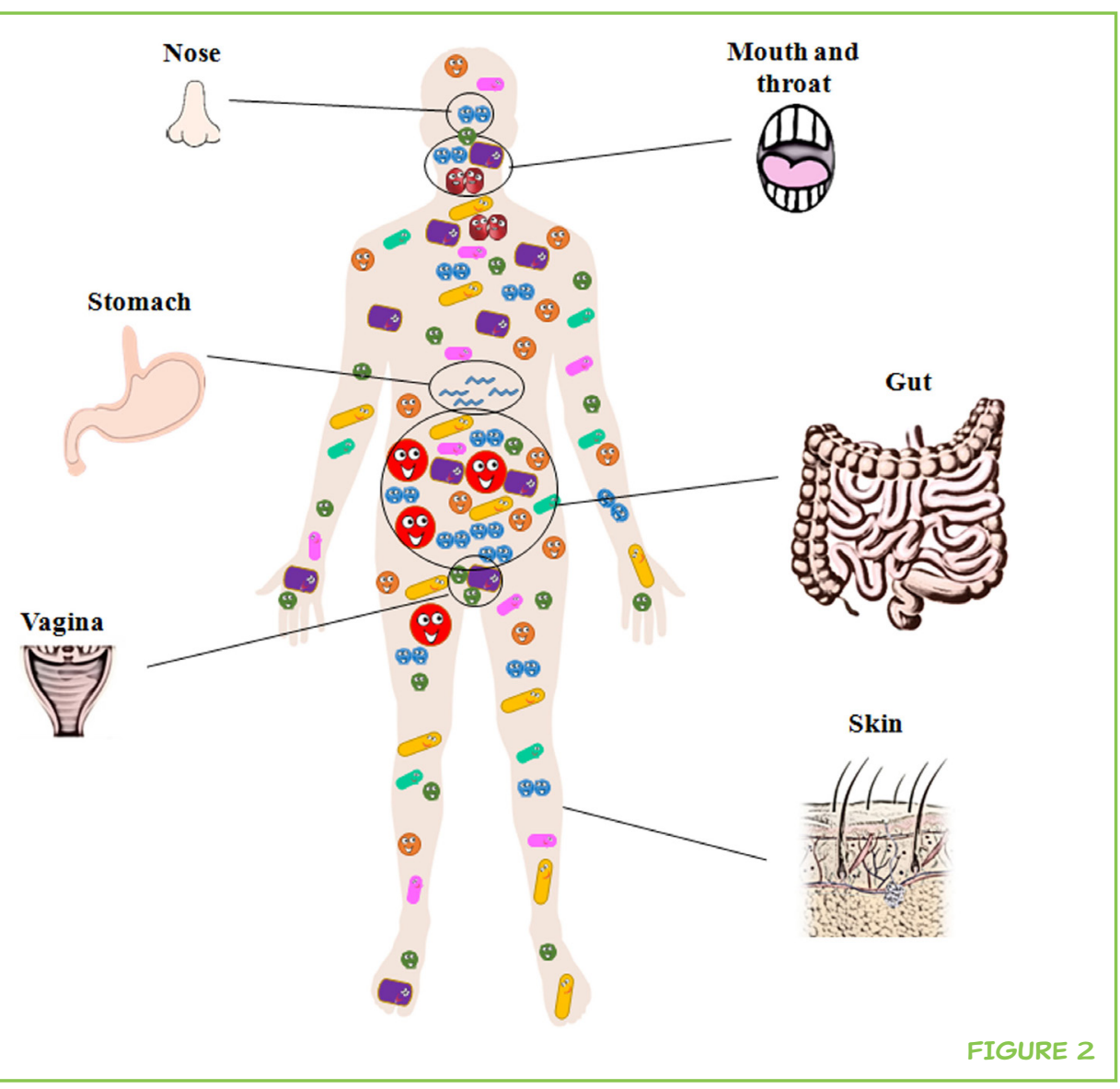

microorganisms from their moms during delivery, when they pass through the vagina, or from contact with the mom's skin, if the delivery is by cesarean section. Lactobacilli, a type of bacteria considered to be one of the "good guys," live in the mother's vagina and they colonize the baby's intestines to help in the digestion of milk, which contains a sugar called lactose. If the baby is delivered by cesarean section, Lactobacilli will not immediately become part of the baby's microbiota, which will be made up mostly by bacteria from the mom's skin and the baby's environment. These differences in a baby's microbiota, resulting from the type of birth that baby experienced, will remain until the baby is $12-24$ months of age. All babies also acquire bacteria from the skin of the nurses and medical doctors and the environment they live in. After babies begin to eat, they get microbes from their diet. In the first days of life, the type of the microorganisms that colonize their intestines will be different, depending whether the baby is breast feeding or drinking formula. Breast feeding is healthy for the baby, because it helps the baby to acquire bacteria from the mother's skin that will then colonize the baby's intestines, and there are also other components of the mother's milk that protect the baby from disease. As babies grow, they get microorganisms from the solid food they eat, from crawling on the floor, from putting their hands in their mouths, from licking toys, and from many other sources! 


\section{FIGURE 3}

Factors that influence our microbiota are showed in the small circles around the middle circle.

During birth, the first microorganisms that we get depend on the birth delivery process (natural or c-section). The baby feeding method (mom's milk or drinking formula) will influence the microbiota in our first years of life. Diet will influence the composition of microbiota in all stages of our life. As we get older (age), microbiota alterations depend on our diet, environment where we live, and life style. Antibiotics will also alter the composition of our gut microbiota (see text for detailed explanation).

\section{BACTERIAL}

INFECTION

A disease caused by pathogenic bacteria.

\section{ANTIBIOTICS}

Special medicines used to fight against bacteria.

\section{PATHOGEN}

Microorganism that causes disease (sometimes also called a germ).

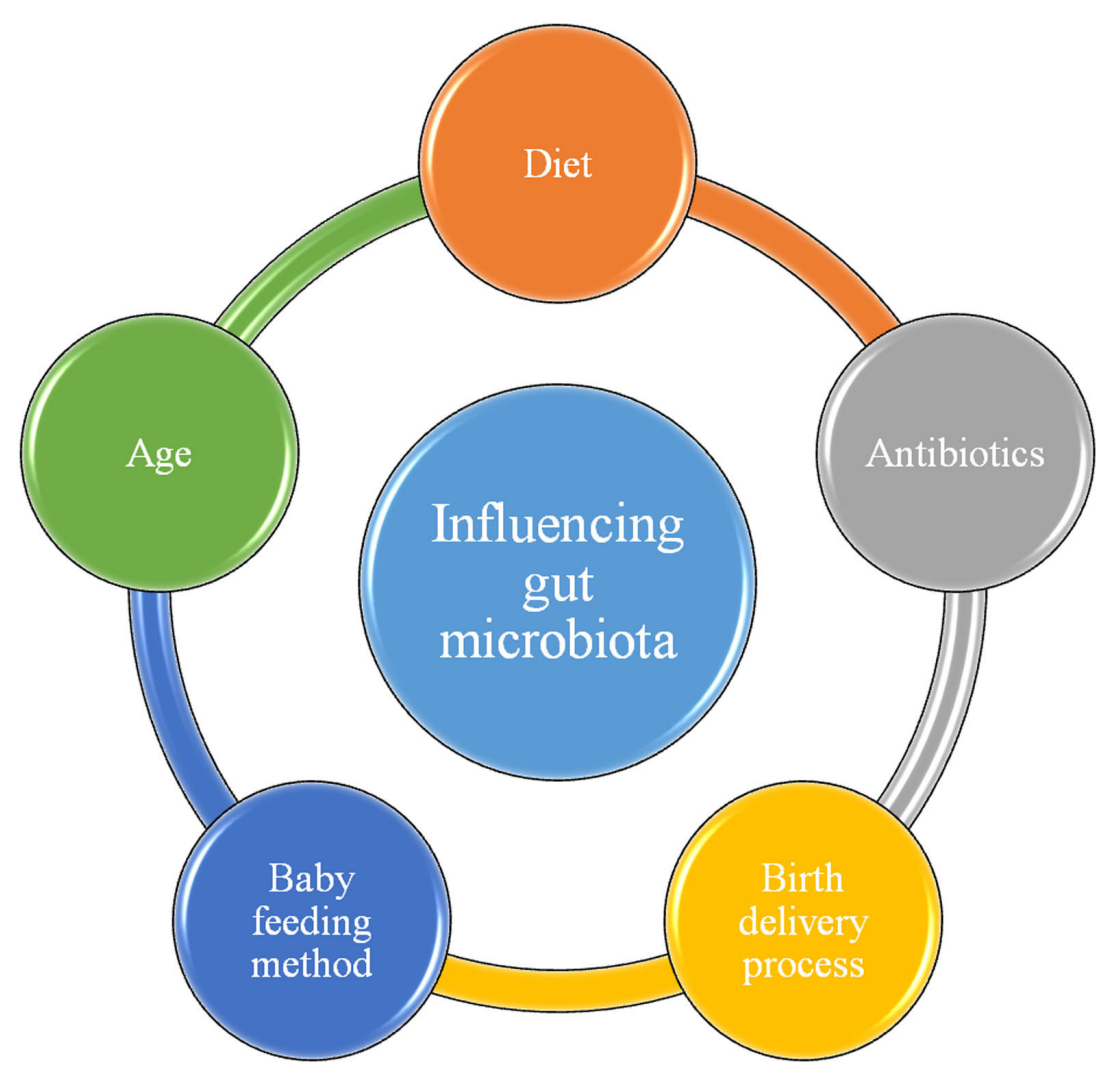

FIGURE 3

The microbes that live in the human body change during our growth, until we are 3 years old. At that point, the microbiota becomes more or less stable until adult life. Each individual has his or her own microbiota, which depends in part, but not only, on the types of food eaten, the environment where the person lives, and the other people and animals that the person interacts with (Figure 3) $[2,3]$.

\section{WHAT IS THE ROLE OF THE HUMAN MICROBIOTA?}

When we mention bacteria in the human body, you might immediately think of a disease, called a bacterial infection. At some point in your life, you have probably had an infection that was treated by antibiotics prescribed by your doctor. Antibiotics are medicines that kill or prevent the growth of bacteria.

However, the majority of the microbes are harmless and actually help to maintain our health. The microbes of the skin, mouth, and nose fight against bad bacteria that want to enter the body to cause disease. These good bacteria act like guards that keep away the harmful bacteria that make us sick. The bacteria that colonize the vagina are another example of good bacteria. They maintain an acidic environment in the vagina that prevents the growth of other microorganisms that might cause disease. Disease-causing microorganisms are called pathogens. 
Even though most of the time they are harmless or even helpful, in certain conditions some of the bacteria that are part of the human microbiota can harm us. For example, bacteria that live on the skin can become a problem. If you cut yourself, the bacteria that live on the surface of your skin may be able to enter into your body through the cut, getting in where they do not belong. In this instance, these bacteria sometimes might be harmful to the body and trigger an infection. Symptoms of an infection include pain, swelling, redness, and fever.

Another example of how the microbiota can harm us is when you let too many bacteria accumulate in your mouth. These bacteria can stick to the surface of your teeth. Some types of bacteria will produce acidic products from the food you eat (especially sugars) that can destroy your teeth and gums. That is why we need to brush our teeth at least two times a day for 3 min to avoid the multiplication of bacteria that can cause painful disease and, in severe cases, loss of teeth.

As we mentioned earlier, the intestines contain the largest portion of the human microbiota. The intestinal microbiota produces some vitamins that are good for us, such as vitamins B12 and K. These vitamins are not produced by human cells. The intestinal microbiota also helps in the digestion of food and protects the intestinal walls from invasion by pathogens.

There is a lot of research going on about the role of the intestinal microbiota. We are still trying to understand how the human microbiota contributes to health and disease. In general, healthy humans have a balanced microbiota, with a high diversity of bacteria in their guts. This means that they have a mix of different types of bacteria with different shapes, sizes, function, and names. More than 1,000 different types of bacteria exist in the human gut! By contrast, when only a small diversity of bacteria is present, meaning that only a few types of bacteria exist in the gut, in higher numbers than normal, disease may occur. Different levels of diversity in the gut bacteria may be related to obesity (the state of being extremely overweight), which can begin in childhood. Abnormal diversity in the intestinal microbiota may also play a role in the development of diabetes (increased sugar in the blood), asthma (long-lasting difficulty with breathing), and painful diseases in the intestine (chronic gut inflammation), among others [4]. As an example, a healthy gut microbiota includes two main groups of bacteria called Firmicutes and Bacteroidetes, but it has been shown that, in the guts of obese people, Bacteroidetes are almost absent.

It is known that a healthy microbiota (which means a microbiota with a huge bacterial diversity, including plenty of good microbes) contributes to our health (Figure 3). Do you want to be healthy? Then you need to take care of your friendly intestinal bacteria. How can you do that? 


\section{PREBIOTICS}

Compounds that help the growth of the good microbes in the gut.

\section{PROBIOTICS}

Live microorganisms are good for our health, especially the digestive system.

\section{TAKING CARE OF THE GUT MICROBIOTA}

Over the last few decades, many of the diseases mentioned above have been increasing. Many of these problems are related to changes in the types of food we eat [5]. We eat a lot of sugar in things like cakes, biscuits, brownies, sweet jellies, and white bread, and we also eat a lot of burgers, meat with fat, and sauces, which, in excess, are not good for our health. These foods are also not good for some of our intestinal microbiota. Some of our microbes need veggies, fibers from beans, chickpeas, cereals, dark bread, seeds, and roots. These types of foods are called prebiotics and they help the growth of the microbiota, feeding bacteria that are able to break down this type of food into the nutrients that can be used by the human body to improve our health. We cannot digest some types of food properly if we do not have our tiny friends in our guts. Therefore, we do not want these good bacteria to die, because they are important to our health balance. The reduction of these good bacteria will allow the growth of the not-so-good bacteria that can eventually cause health problems.

Probiotics can help you replace the lost good microbiota. Probiotics are live bacteria that are good for us, that balance our good and bad intestinal bacteria, and that aid in digestion of food and help with digestive problems, such as diarrhea and bellyache. Bacteria that are examples of probiotics are Lactobacilli and Bifidobacterium. You can find probiotics in some foods, such as yogurts, sourdough bread, buttermilk, and sour pickles. Some infant formulas are also supplemented with probiotics, despite the fact that we do not really know yet how helpful they are in diseases of babies.

Antibiotics are medicines we take to treat infections caused by bacteria. Antibiotics are not active against infections by fungi or viruses. So, do antibiotics kill our good bacteria friends too? Yes, they do [3]. However, if we have a bacterial infection, we have to treat it, so in many cases we must take antibiotics. Be sure to only take antibiotics when your doctor says you really need to, and take them during the time he advises. You do not need an antibiotic to treat a cold or the flu, because these diseases are caused by viruses. People who take a lot of antibiotics may get sick because the antibiotics destroy lots of the bacteria in their bodies, including the good ones. When lots of the bacteria in the gut are killed, the gut then has more free space and available food for the bad bacteria, which can then multiply. When these bad bacteria reach higher numbers, they can sometimes cause disease. As a consequence, individuals taking antibiotics frequently get diarrhea or more complicated intestinal diseases. When you take antibiotics without needing to do so, you might contribute to the emergence of "superbugs," which are bacteria that are not killed by the majority of the antibiotics available today. These superbugs can survive in the presence of the antibiotic (which is called resistance to the antibiotic), so the infection continues even when the antibiotics are being used. 


\section{CONCLUSION}

Humans need a diverse and balanced microbiota in their intestines to keep them healthy. Kids or adults who eat a lot of sugar and fats, but not veggies, and who do not have balanced nutrition, tend to become obese or to develop some diseases, even later in life. Do not take antibiotics without a prescription from your doctor. Always eat a healthy, balanced diet and never forget to include some green, orange, and red on your plate: make your plate colorful. With these tips, you will be taking the best care of your microbiota!

\section{REFERENCES}

1. Human Microbiome Project Consortium. 2012. A framework for human microbiome research. Nature 486(7402):215-21. doi:10.1038/nature11209

2. Tamburini, S., Shen, N., Wu, H. C., and Clemente, J. C. 2016. The microbiome in early life: implications for health outcomes. Nat. Med. 22(7):713-22. doi:10.1038/nm.4142

3. Blaser, M. J. 2014. Missing Microbes: How the Overuse of Antibiotics is Fueling Our Modern Plagues. Toronto, Ontario: HarperCollins Publishers, 273.

4. Motta, J. P., Flannigan, K. L., Agbor, T. A., Beatty, J. K., Blackler, R. W., Workentine, M. L., et al. 2015. Hydrogen sulfide protects from colitis and restores intestinal microbiota biofilm and mucus production. Inflamm. Bowel Dis. 21(5):1006-17. doi:10.1097/MIB.0000000000000345

5. Kumar, M., Babaei, P., Ji, B., and Nielsen, J. 2016. Human gut microbiota and healthy aging: recent developments and future prospective. Nutr. Healthy Aging 4(1):3-16. doi:10.3233/NHA-150002

SUBMITTED: 08 May 2017; ACCEPTED: 28 June 2017; PUBLISHED ONLINE: 17 July 2017.

EDITED BY: Robert T. Knight, University of California, Berkeley, United States

CITATION: da Silva GJ and Domingues S (2017) We Are Never Alone: Living with the Human Microbiota. Front. Young Minds 5:35. doi:10.3389/frym.2017.00035

CONFLICT OF INTEREST STATEMENT: The authors declare that the research was conducted in the absence of any commercial or financial relationships that could be construed as a potential conflict of interest.

COPYRIGHT @ 2017 da Silva and Domingues. This is an open-access article distributed under the terms of the Creative Commons Attribution License (CC BY). The use, distribution or reproduction in other forums is permitted, provided the original author(s) or licensor are credited and that the original publication in this journal is cited, in accordance with accepted academic practice. No use, distribution or reproduction is permitted which does not comply with these terms. 


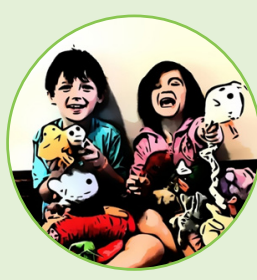

\section{REVIEWED BY}

\section{JACK AND ADDY, 7 AND 6 YEARS OLD}

Jack and Addy attend St. Anthony Park Elementary School. Jack enjoys science, history, hockey, and Legos. Addy enjoys reading, gymnastics, hockey, and figure skating.

Appropriately, they share a large collection of stuffed microbes!

\section{AUTHORS}

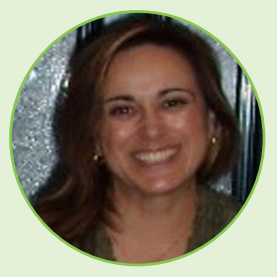

\section{GABRIELA JORGE DA SILVA}

My name is Gabriela Jorge da Silva and I have been a Professor and a researcher in the Bacteriology field for more than 20 years at the Faculty of Pharmacy of the University of Coimbra, Portugal. The focus of my research has been the genetic study of antimicrobial resistance and how it is spread, and the discovery of new antibacterial compounds. More recently, I have been interested in the impact of antibiotics and diet compounds on human health, specifically on the gut microbiota. I like to learn and share scientific knowledge. *gjsilva@ci.uc.pt

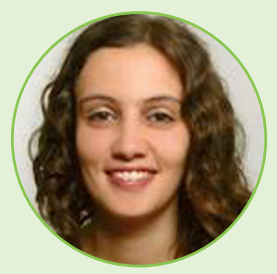

\section{SARA DOMINGUES}

My name is Sara Domingues and I am a professor of Microbiology in the Faculty of Pharmacy, University of Coimbra, Portugal. I have been working in the microbiology field for almost 10 years, and have been focusing on the transfer of genetic material between bacteria, which could impact the efficiency of antibiotics and also impact our health. I am fascinated by the fact that such tiny living organisms such as bacteria are so important for us and that they can be involved in so many different activities. I like to understand bacteria in order to figure out whether we can improve our health with bacteria's help! 